\title{
The Urological Management of Spinal Cord Damaged Patients: a Clinical Algorithm
}

B. P. Gardner, M.A., B.M., B.CH., M.R.C.P., F.R.C.S., ${ }^{1}$ K. F. Parsons, M.B.B.S., F.R.C.S., ${ }^{2}$ D. G. Machin, M.B.B.S., F.R.C.S., ${ }^{3}$ A. Galloway, B.Sc(Hons.), M.B.B.S., ${ }^{4}$ K. R. Krishnan, M.B.B.S., F.R.C.S.E. ${ }^{5}$

${ }^{1}$ Senior Registrar in Spinal Injuries, ${ }^{5}$ Director, Mersey Regional Spinal Injuries Centre, Southport, Merseyside, U.K. ${ }^{2}$ Consultant Urologist, ${ }^{3}$ Urological Registrar, Royal Liverpool Hospital, Liverpool, U.K. ${ }^{4}$ Consultant Microbiologist, Whiston Hospital, Liverpool, U.K.

\section{Summary}

A scheme for the management of the common urological presentations encountered in spinal cord damaged patients is provided in flow chart form. The diagrams indicate how urological investigations can be used to greatest effect. A simple computer programme based on these charts is available.

Key words: Urological; Management; Algorithm.

\section{Introduction}

There are five common urological presentations seen in spinal cord injured patients with vesico-urethral neuropathy.

These are:

1. Inability to void on removal of the catheter during the first admission after injury.

2. Acute urinary retention having previously voided satisfactorily.

3. Difficulty in voiding despite having a sterile urinary tract.

4. Asymptomatic upper tract dilatation discovered on routine follow-up intravenous urography.

Our management of these problems has evolved over a period of 37 years since 1947, during which time diagnosis and treatment has depended on close liaison between the staff of the Regional Urological Centre and the Regional Spinal Injuries Centre (Abel et al., 1974; Gibbon et al., 1965; Ross, 1976; Ross and Damanski, 1953; Ross et al., 1957, 1964, 1967). Over 1100 patients have been treated. Urological assessments are performed annually. This paper presents in schematic form, flow charts of the urological management of these cases. The charts demonstrate the selection of patients for sophisticated urological evalua-

Requests for Reprints: B. P. Gardner, National Spinal Injuries Centre, Stoke Mandeville Hospital, Aylesbury, Bucks, England. 
tion and indicate the treatment programmes based on the results of these tests. The following sections elucidate the contents of each chart.

\section{Urological presentations}

1. Inability to pass urine during the initial admission following injury (Chart 1).

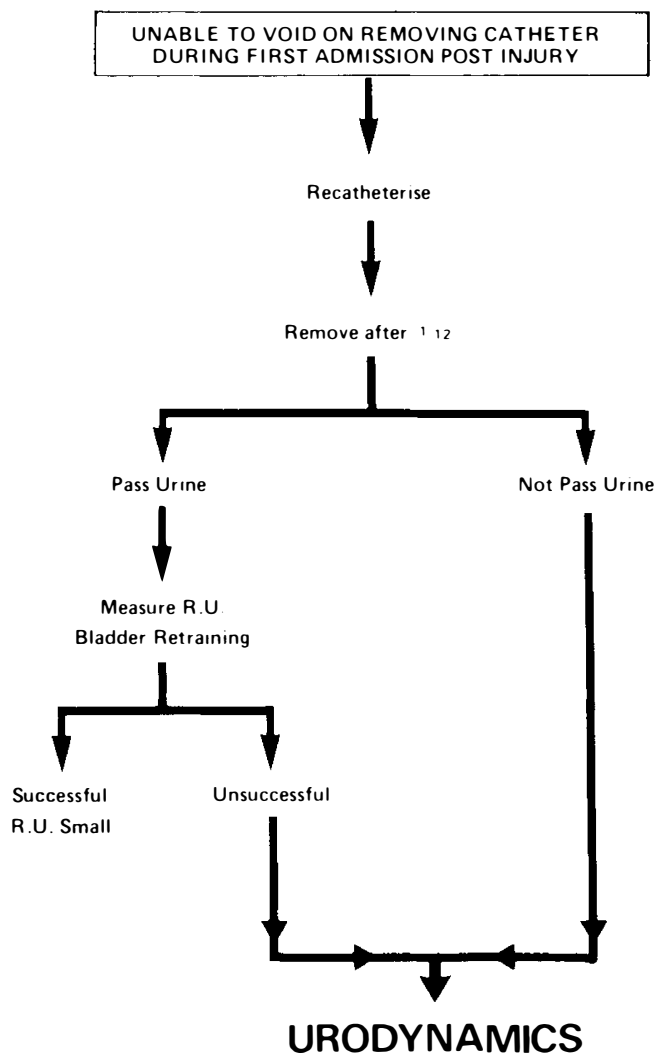

Chart 1

It is a truism that all patients with acute major spinal cord injury are threatened with urinary retention and should be catheterised immediately. Initial overstretching of the detrusor prolongs the interval preceding recovery of bladder contractility.

Intermittent catheterisation is used whenever possible during the acute phase (Guttmann and Frankel, 1966: Wyndaele et al., 1985). This ideal cannot always be achieved and in these cases the concept of trial without catheter is applied. A period of one month is allowed in most patients in whom micturitition is not established before a further trial is attempted.

Once micturition occurs then the definition of 'successful' and 'unsuccessful' becomes crucial. We consider a 'small' residual volume to be less than $50 \mathrm{ml}$, but this is by no means precise. The absolute value of the residual urine is not of critical importance provided that the upper urinary tracts are not compromised, 
the patient has no difficulty voiding and urinary sterility is maintained. These three requirements are in our experience, however, usually only found in those patients with a residual urine of less than $50 \mathrm{ml}$ and therefore larger volumes tend to alert our attention towards further investigation of bladder function.

We recognise that some patients may have a small residual urine with normal biochemical and intravenous urographic parameters and yet have a hypertonic bladder on filling, and void at high detrusor voiding pressures. We consider that this situation is unusual and provided that the upper tracts are regularly assessed, permanent renal impairment will not arise. We find it impractical to investigate by urodynamics all patients who appear to have normal voiding and have low residual urinary volumes.

\section{Acute urinary retention having previously voided satisfactorily (Chart 2)}

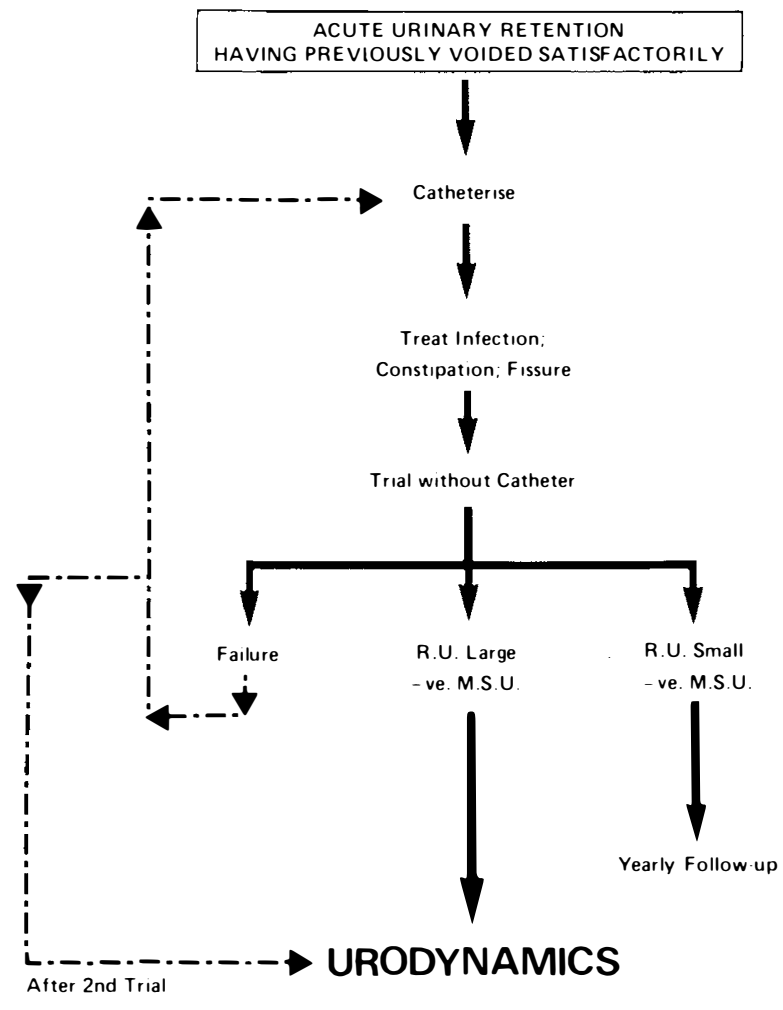

Chart 2

At any stage a patient with a neuropathic bladder may suddenly develop acute urinary retention having previously been voiding satisfactorily. This may be precipitated by urinary infection, constipation or perianal pathology such as an anal fissure. These conditions should be treated before a trial without catheter is undertaken. As the length of survival of spinal cord injured persons increases, more will fall into the 'prostatic' age group and this may become a contributory factor producing retention. 
Further investigation, as demonstrated in Chart 2, is required if adequate treatment of precipitating causes does not result in satisfactory voiding.

3. Patients presenting with difficulty voiding despite having sterile urine (Chart 3)

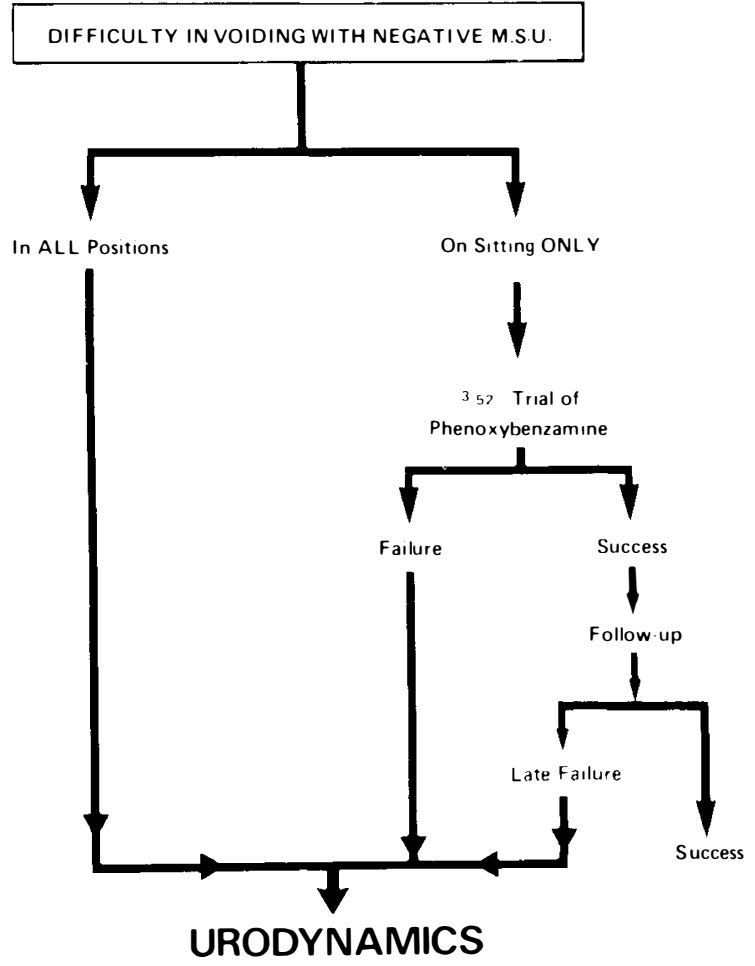

Chart 3

Spinal cord injured patients lack normal visceral sensation, but can be acutely aware that their micturition is unsatisfactory. Some patients with difficulty in voiding may experience this predominantly or exclusively in the sitting position. These patients may have urethral decentralisation supersensitivity to circulating alpha adrenergic agonists and therefore may benefit from phenoxybenzamine (Parsons and Turton, 1980; Sham Sunder et al., 1978). This drug must be taken for at least three weeks for its optimum effect to be established. It should be noted from Chart 3 that some patients who initially benefit from phenoxybenzamine may subsequently develop further difficulties. It is possible in these cases that the urethral muscle develops supersensitivity to other circulating agonists that are not blocked by phenoxybenzamine.

4. Asymptomatic upper tract dilatation detected at routine follow-up intravenous urography (Chart 4)

Upper tract dilatation may be caused by chronic infection, bilateral vesicoureteric reflux, obstruction in the intramural ureter or ureteric orifice, or at the 


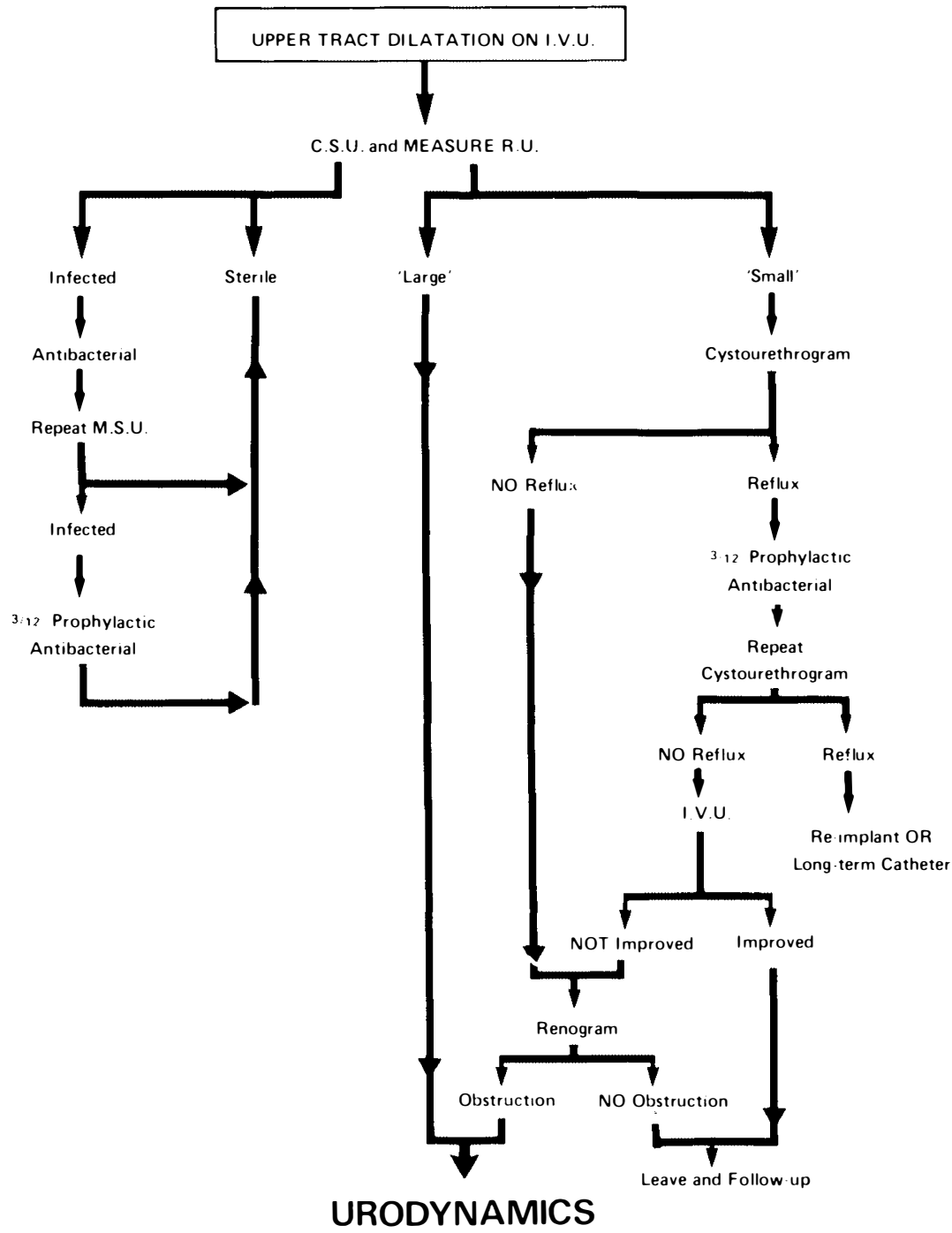

Chart 4

bladder outlet. The management of such cases is outlined in Chart 4 . In the absence of reflux, renographic assessment provides confirmatory evidence of obstruction.

It should be noted on this chart that some patients, whose reflux persists despite antibacterial therapy, require long term catheterisation rather than reimplantation. Although the latter is the treatment of choice, it may not succeed in preventing reflux when the bladder is grossly trabeculated.

Prophylactic antibacterial therapy is widely used (Asscher, 1980; Gruneberg, 1980) and is part of the established practice of our centre.

5. Recurring urinary tract infections in non-catheterised patients (Charts 5 and 6) Spinal cord damaged patients with indwelling urethral catheters usually have 


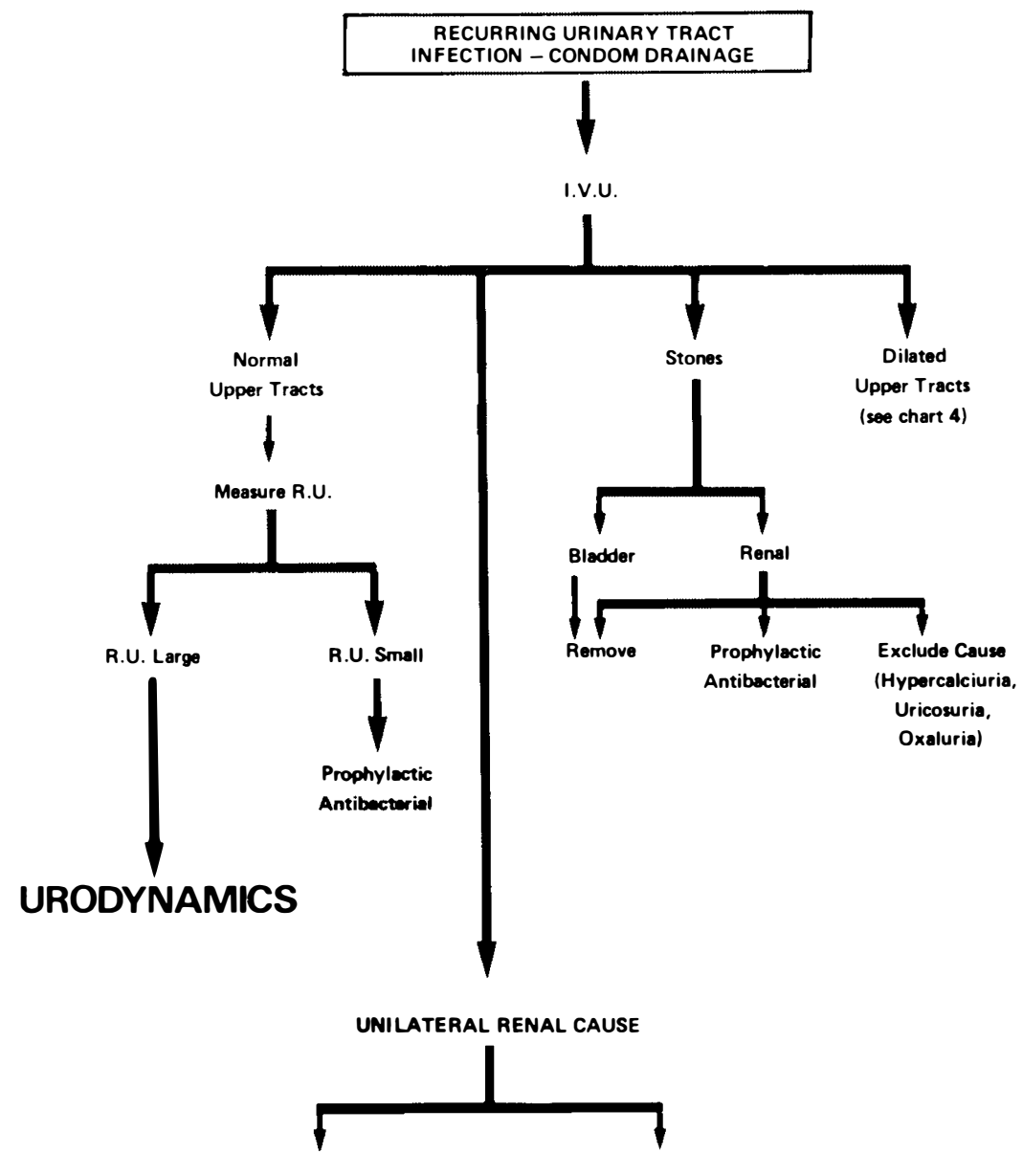

Chart 5

infected urine. This infection requires treatment only when symptomatic. By contrast, the urine of all other patients should be maintained sterile.

The preservation of renal tissue in spinal cord damaged patients is vital since renal failure remains an important major cause of death. Hence, when investigation indicates that unilateral renal pathology is the probable basis for the recurring infection, nephro-ureterectomy is rarely indicated. There are two circumstances, however, when removal of the kidney and ureter is absolutely essential. Firstly, when pyonephrosis is demonstrated in a poorly functioning renal unit, and secondly when antibacterial therapy has failed to clear infection in an upper tract proven by urine sampling to be the only site of infection and by renography to have poor function. 


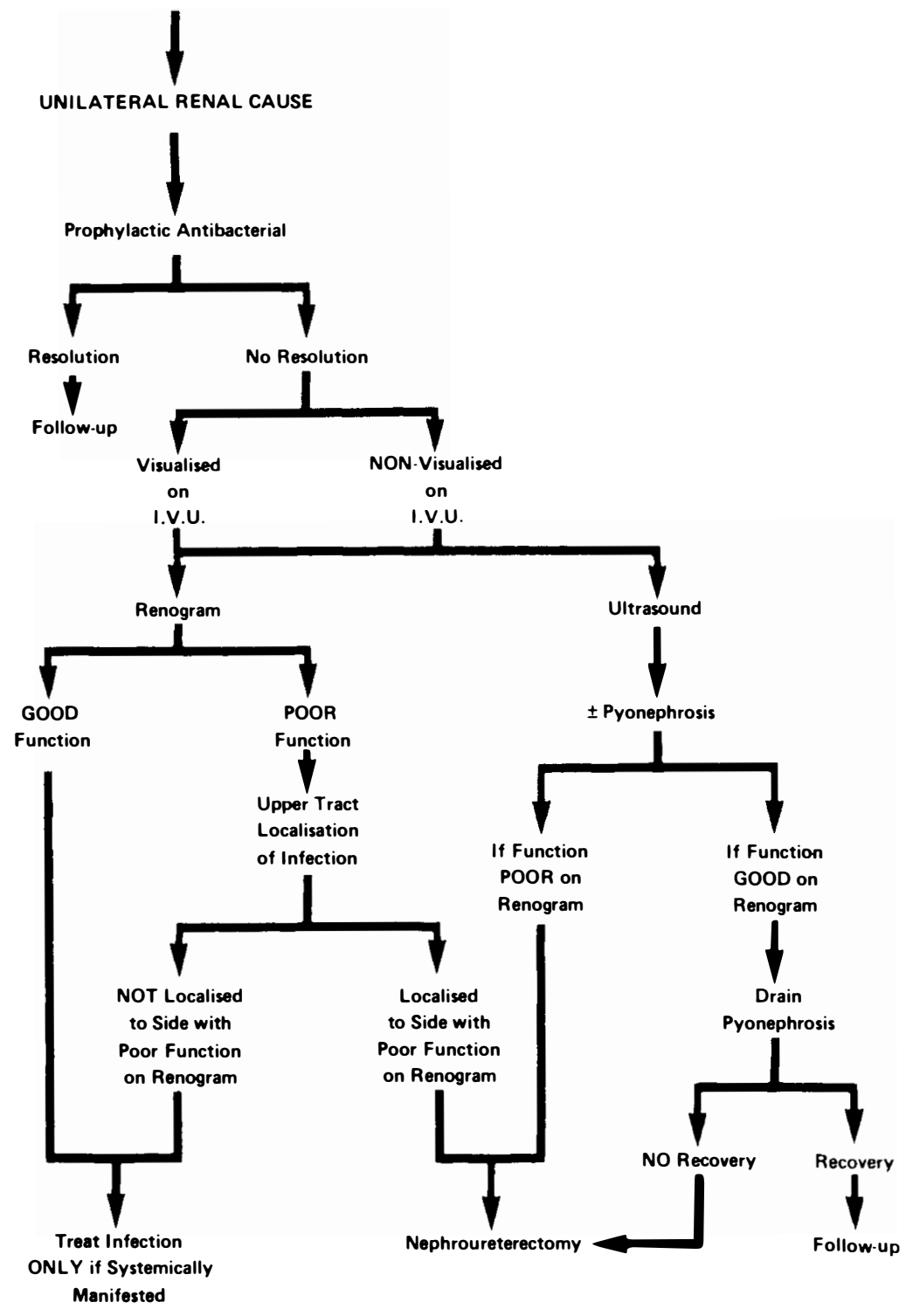

Chart 6 
6. Urodynamics and cystourethrography (Charts 7 and 8)

INPUT FROM

PRESENTATIONS

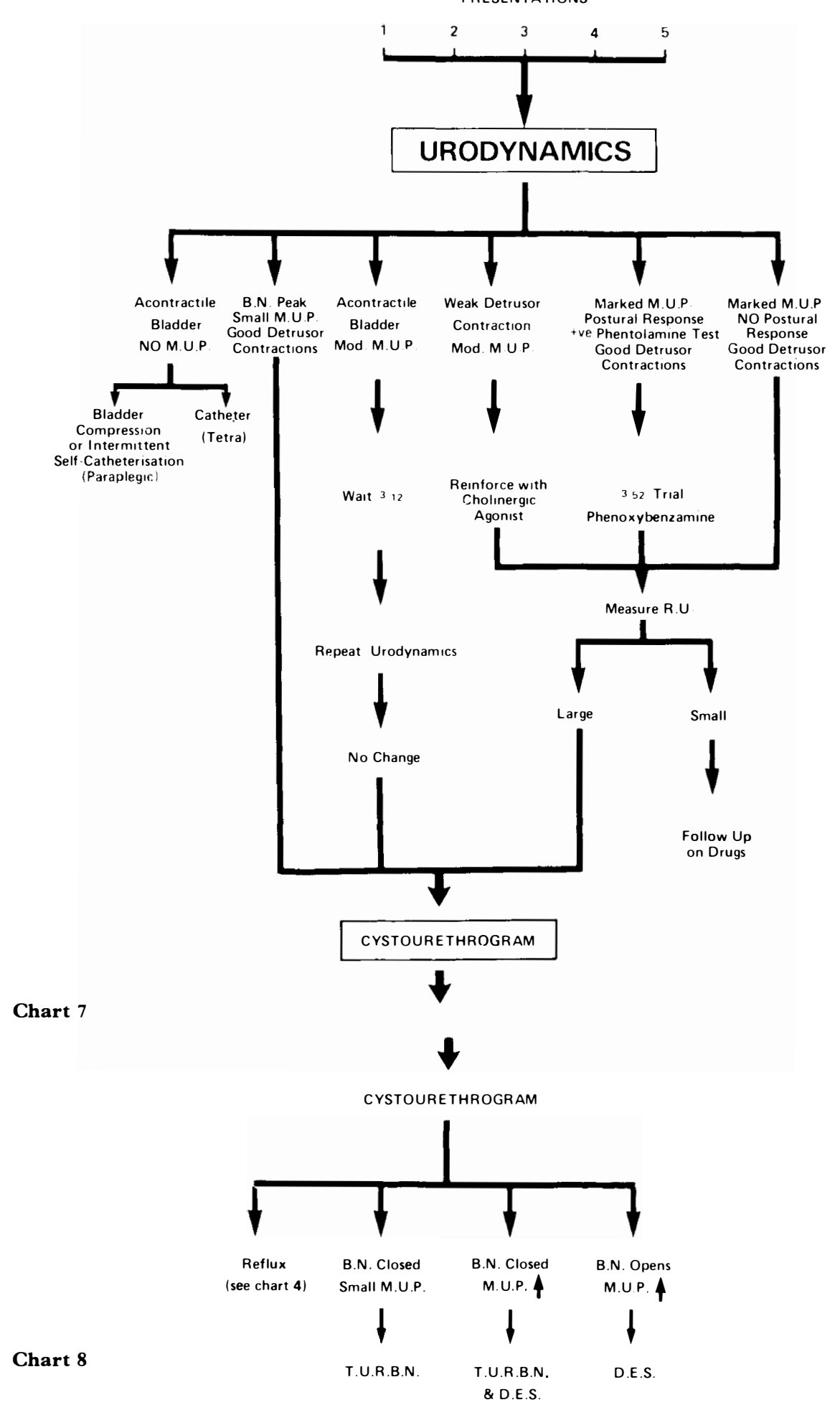


Charts 7 and 8 indicate the management of the bladder and urethra of spinal cord damaged patients that we have developed over the last several years (Abel et al., 1975; Gardner et al., 1984; Gibbon, 1973; Gibbon et al., 1980; Ross et al., 1976). The treatment options are derived from following the programmes outlined in Chart 7 , which indicates the variety of urodynamically measured responses, and Chart 8 , which outlines the cystourethrographic findings.

Clearly, not all patients come to surgery and these can be selected by the urodynamic assessments. The urodynamic tests include an assessment of the responses of the urethra to intravenous alpha-blocking agents, for example phentolamine. On this basis the option of a long-term oral alpha-blocking agent, with or without a cholinergic agonist, occasionally suffices. Phenoxybenzamine is the long term oral alpha-blocking agent and Distigmine the cholinergic agonist most widely used in our unit. Continued vigilance is essential as late failure may occur with phenoxybenzamine and cholinergic agonists may increase the M.U.P. in lower motor neurone lesions and increase detrusor sphincter dyssynergia in upper motor neurone cases.

The remaining cases have a radiographic assessment of the outflow and proceed to one of the three surgical options shown in Chart 8 . These options are derived from following the programmes outlined in Chart 7, which indicates the variety of urodynamically measured responses.

\section{Discussion}

Urological problems are still a major source of morbidity and mortality in spinal cord damaged patients. The pathophysiological processes involved are only partly understood and as a result treatment is often unsuccessful.

The availability of complex investigations is limited and it is not possible to investigate all patients exhaustively. It is essential to restrict the resources to those most likely to benefit. Doctors with little experience in the management of spinal cord injured patients may find difficulty in selecting appropriate investigations and treatment. These charts provide a simple logical answer to this problem and outline an optimum scheme for investigation of the various urological presentations encountered.

Charts such as these have enabled us to create simple computer programmes based on them. These programmes can have both practical and didactic value.

\section{References}

Abel BJ, Gibbon NOK, Jameson RM, KRishnan KR 1974 The neuropathic urethra. Lancet 2:1229-1230.

Abel BJ, Ross J.Cosbie, Gibbon NOK, Jameson RM 1975 Urethral pressure measurement afer division of the external sphincter. Paraplegia 13:37-41.

ASSCHER AW 1980 Prophylaxis of urinary tract infection. Proceedings of the International Symposium 'The challenge of Urinary Tract Infection', Published by The Medicine Publishing Foundation, Edited by A. W. Asscher 63-71.

GARDNER BP, PARSONS KF, MAChIN DG, JAMESON RM, KRISHNAN KR 1984 The role of urodynamics in the management of spinal cord injured patients. Paraplegia 22:157-161.

GibBon NOK, Ross JC, DAMANSKI M 1965 Bladder neck resection in the paraplegic-report of over 100 cases. International Journal of Paraplegia 2:264-278.

GibBON NOK 1973 Division of the external sphincter. British Journal of Urology 45:110-115.

Gibbon NOK, Parsons KF, Woolfenden KA 1980 The neuropathic urethra. Paraplegia 18:221-225. 
GRUNEBERG RN 1980 Extended treatment of urinary tract infection. Proceedings of the International Symposium 'The challenge of Urinary Tract Infection', Published by The Medicine Publishing Foundation, Edited by A. W. Asscher 73-80.

Guttmann L, Frankel H 1966 The value of intermittent catheterisation in the early management of traumatic paraplegia and tetraplegia. Paraplegia 4:63-83.

PARSONS KF, TURTON MB 1980 Urethral super-sensitivity and occult urethral neuropathy. British Journal of Urology 52:131-137.

Ross JC 1956 Treatment of the bladder in paraplegia. British Journal of Urology 28:14-23.

Ross JC, Damanski M 1953 Pudendal neurectomy in the treatment of the bladder in spinal injury. British Journal of Urology 25:45-50.

Ross JC, GibBon NOK, Damanski M 1957 Resection of the external urethral sphincter in the paraplegic. Preliminary report. Transactions of the American Association of Genito-Urinary Surgeons 69:193-198.

Ross JC, Gibbon NOK, Damanski M 1964 Bladder dysfunction in non-traumatic paraplegia. Lancet 779-782.

Ross JC, Gibbon NOK, Damanski M 1967 Division of the external sphincter in the treatment of the neurogenic bladder-a ten year review. British Journal of Surgery 54:627-828.

Ross JC, Gibbon NOK, Sham Sunder G 1976 Division of the external urethral sphincter in the neuropathic bladder - a twenty years' review. British Journal of Urology 48:649-656.

Sham Sunder G, Parsons KF, Gibbon NOK 1978 Outflow obstruction in neuropathic bladder dysfunction: the neuropathic urethra. British Journal of Urology 50:190-199.

Wyndaele J, De Sy WA; Claessens M 1985 Evaluation of different methods of bladder drainage used in the early care of spinal cord injury patients. Paraplegia 23:18-26

\section{Acknowledgements}

We acknowledge the contributions of Mr J. C. Ross and Mr N. O. K. Gibbon to the urological management of the patients of the Mersey Regional Spinal Injuries Centre. 